\title{
RELATING BODY SIZE TO THE RATE OF HOME RANGE USE IN MAMMALS ${ }^{1}$
}

\author{
Robert K. Swihart ${ }^{2}$, Norman A. Slade, and Bradley J. Bergstrom ${ }^{3}$ \\ Museum of Natural History and Department of Systematics and Ecology, \\ The University of Kansas, Lawrence, Kansas 66045 USA
}

\begin{abstract}
The area occupied or traversed by an animal is a function of the time period considered, but few empirical estimates of the temporal component of home range use are available. We used a statistic called the "time to independence" to make an ecologically meaningful estimate of the amount of time required for an individual to traverse its home range. Data from 23 species of terrestrial mammals indicated the existence of a sizedependent time scale governing the rate of home range use. Foraging mode influenced the rate of home range use; central place foragers traversed their home ranges approximately five times as rapidly as comparably sized noncentral place foragers.

Numerous physiological measures of time are related to body mass raised to the $1 / 4$ power. Our results suggest that the time scale governing the rate of space use by mammals is related similarly to body mass. This relationship permits a more critical examination of factors thought to influence home range size, including habitat productivity and social organization.
\end{abstract}

Key words: allometry; biological time; home range; mammals; space use; statistical independence.

\section{INTRODUCTION}

Body size $(M)$ constrains much of an animal's biology, because it influences physiological requirements and imposes morphological and ecological limits on how those requirements are satisfied. Many physiological measures of time, including heartbeat duration, muscle contraction time, nerve conduction time, and time of food passage through the gut (Blueweiss et al. 1978, reviewed in Lindstedt and Calder 1981), are related to body mass. Moreover, all of these time measures are related to body mass raised to approximately the $1 / 4$ power. Size-dependent scaling of time is not restricted to physiological processes. Ecologically meaningful units of time, such as population doubling time and intrinsic rate of increase (1/time), also scale approximately as $Y=a M^{1 / 4}$ (Blueweiss et al. 1978, Eisenberg 1981, Western 1979, Calder 1984).

Recently, Lindstedt et al. (1986) invoked temporal scaling of movements to explain observed relationships between home range size and body mass in mammals. They contended that timing of use of the home range, $t$, should scale with mass raised to the $1 / 4$ power, consistent with other measures of biological time. Note that $t$ is distinct from the time span over which investigators define home range. Researchers temporally delimit home ranges using a somewhat arbitrary chronological measure of time (e.g., a year), whereas $t$ mea-

\footnotetext{
'Manuscript received 29 September 1986; revised 5 June 1987; accepted 7 June 1987.

2 Present address: Department of Plant Pathology and Ecology, The Connecticut Agricultural Experiment Station, P.O. Box 1106, New Haven, Connecticut 06504 USA.

${ }^{3}$ Present address: Department of Biology, Valdosta State College, Valdosta, Georgia 31698 USA.
}

sures the temporal component of home range use as determined by the animal. While these two measures of time may coincide, there is no a priori reason they should.

A critical evaluation of home range allometry requires an empirical estimate of the temporal component of space use. In this paper, we estimate this temporal component for 23 species of mammals, determine whether a size-dependent clock influences movements, and consider how this clock interacts with other factors that influence home range size.

\section{METHODS}

We analyzed movement data for 23 species ranging in body mass from $30 \mathrm{~g}$ to $70 \mathrm{~kg}$ (Table 1). Following $\mathrm{McNab}$ (1963), we classified species as croppers if they were primarily herbivorous (grazers, browsers) and hunters if they relied primarily upon foods such as seeds, fruits, or mobile prey. Species also were categorized as central place foragers (CPF) or not (nonCPF). For all species, movements were monitored either by radiotelemetry or direct observation, and locational information was collected at short sampling intervals (Table 1), resulting in successive observations that were autocorrelated. Observations were collected only during periods of activity. Body masses $(M)$ were taken from original sources when available; otherwise, species averages were used. Jackknifed estimates of home range area $(A)$ were calculated to reduce somewhat the biases associated with outliers (Swihart and Slade 1987). We used the minimum convex polygon measure of home range because of its relative robustness when used with autocorrelated data (Swihart and Slade 1985a).

Previous studies of home range allometry relied on 
TABLE 1. Body mass, home range size, and the time required to traverse a home range during the course of normal movements $(T T I)$ for 23 species of mammals.

\begin{tabular}{|c|c|c|c|c|c|c|c|c|}
\hline \multirow[b]{2}{*}{ Species } & \multirow[b]{2}{*}{$N$} & \multirow{2}{*}{$\begin{array}{c}\text { Body } \\
\text { mass }(\mathrm{kg})\end{array}$} & \multicolumn{2}{|c|}{ Home range (ha) } & \multicolumn{2}{|c|}{ Time $(T T I, \mathrm{~min})$} & \multirow{2}{*}{$\begin{array}{l}\text { Trophic } \\
\text { class* }\end{array}$} & \multirow{2}{*}{$\begin{array}{c}\text { Foraging } \\
\text { modet }\end{array}$} \\
\hline & & & $\overline{\bar{X}}$ & (SD) & $\bar{X}$ & (SD) & & \\
\hline Ursus americanus & 2 & 69.2 & $2285 \ddagger$ & $(1577)$ & 1860 & $(85)$ & $\mathrm{H}$ & nonCPF \\
\hline Antilocapra americana & 3 & 50.3 & $1142 \ddagger$ & $(437)$ & 860 & $(312)$ & $\mathrm{C}$ & nonCPF \\
\hline Canis latrans & 9 & 12.6 & $618.5 \ddagger$ & $(252)$ & 207 & (162) & $\mathrm{H}$ & nonCPF \\
\hline Cercocebus albigena & 6 & 8.5 & $126.9 \S$ & $(97.4)$ & 534 & (68) & $\mathrm{H}$ & nonCPF \\
\hline Procyon lotor & 5 & 8.0 & $430.2 \ddagger$ & $(149)$ & 1168 & $(528)$ & $\vec{H}$ & nonCPF \\
\hline Urocyon cinereoargenteus & 5 & 2.8 & $548.0 \ddagger$ & $(274)$ & 516 & $(202)$ & $\mathrm{H}$ & nonCPF \\
\hline Lepus californicus & 5 & 2.7 & $156.0 \ddagger$ & $(38)$ & 351 & $(226)$ & $\mathrm{C}$ & nonCPF \\
\hline Lepus americanus & 6 & 1.5 & $53.8 \ddagger$ & (56.4) & 576 & $(507)$ & $\mathrm{C}$ & nonCPF \\
\hline Cynomys ludovicianus & 3 & 1.1 & $1.33 \S$ & $(0.41)$ & 120 & (30) & $\mathrm{C}$ & nonCPF \\
\hline Spermophilus columbianus & 3 & 0.4 & $1.4 \S$ & $(0.18)$ & 427 & (12) & $\mathrm{C}$ & nonCPF \\
\hline Spermophilus beecheyi & 4 & 0.3 & $0.17 \S$ & $(0.04)$ & 188 & $(106)$ & $\mathrm{H}$ & nonCPF \\
\hline Geomys attwateri & 4 & 0.2 & $0.01 \ddagger$ & $(0.01)$ & 165 & $(90)$ & $\mathrm{C}$ & nonCPF \\
\hline Tamiasciurus hudsonicus & 2 & 0.2 & $0.49 \ddagger$ & $(0.01)$ & 63 & (11) & $\mathbf{H}$ & $\mathrm{CPF}$ \\
\hline Ochotona princeps & 4 & 0.15 & $0.16 \S$ & $(0.16)$ & 22 & (17) & $\mathrm{C}$ & CPF \\
\hline Sigmodon hispidus & 2 & 0.12 & $0.59 \ddagger$ & $(0.21)$ & 272 & (18) & C & nonCPF \\
\hline Dipodomys ingens & 2 & 0.11 & $0.05 \S$ & $(0.01)$ & 45 & (7) & $\mathrm{H}$ & CPF \\
\hline Tamias quadrivittatus & 2 & 0.07 & $6.73 \ddagger$ & $(6.85)$ & 82 & (18) & $\mathrm{H}$ & CPF \\
\hline Tamias umbrinus & 4 & 0.06 & $4.55 \ddagger$ & (2.64) & 75 & (14) & $\mathrm{H}$ & CPF \\
\hline Tamias minimus & 2 & 0.04 & $2.10 \ddagger$ & $(0.09)$ & 45 & $(0)$ & $\mathrm{H}$ & $\mathrm{CPF}$ \\
\hline Tamias striatus & 1 & 0.09 & $0.08 \S$ & $\cdots$ & 22 & $\cdots$ & $\mathrm{H}$ & CPF \\
\hline Microtus pennsylvanicus & 2 & 0.04 & $0.02 \ddagger$ & $(0.01)$ & 210 & $(85)$ & C & nonCPF \\
\hline Microtus ochrogaster & 4 & 0.04 & $0.11 \ddagger$ & $(0.04)$ & 211 & $(105)$ & $\mathrm{C}$ & nonCPF \\
\hline Synaptomys cooperi & 1 & 0.04 & $0.05 \ddagger$ & $\cdots$ & 230 & $\cdots$ & $\mathrm{C}$ & nonCPF \\
\hline
\end{tabular}

${ }^{*} \mathrm{H}=$ hunter and $\mathrm{C}=$ cropper (after McNab 1963).

$\dagger \mathrm{CPF}=$ central place forager, nonCPF $=$ not a central place forager.

$\ddagger$ Data from telemetry studies.

$\S$ Data from observational studies.

published estimates of home range size that used a variety of methods of data collection and home range estimation (McNab 1963, Harestad and Bunnell 1979, Gittleman and Harvey 1982, Lindstedt et al. 1986, Swihart 1986). As pointed out by Lindstedt et al. (1986), size-dependent differences in data collection methods among studies may lead to biased regression coeffcients. Similarly, differing techniques of estimating home range size could lead to inaccurate coefficients. By standardizing the home range statistic used and omitting mark-recapture studies from consideration, we hoped to avoid some of the problems in other studies of home range allometry.

To assess the temporal component of home range use, we iteratively measured the level of bivariate autocorrelation between points separated by a specified time interval ( $\Delta t$, in minutes) using Schoener's $t^{2} / r^{2}$ ratio (Schoener 1981), where $t^{2}$ and $r^{2}$ are given by:

$$
\begin{aligned}
t^{2}= & \frac{1}{m} \sum_{i=1}^{m}\left(X_{i+1}-X_{i}\right)^{2} \\
& +\frac{1}{m} \sum_{i=1}^{m}\left(Y_{i+1}-Y_{i}\right)^{2} \\
r^{2}= & \frac{1}{n-1} \sum_{i=1}^{n}\left(X_{i}-\bar{X}\right)^{2} \\
& +\frac{1}{n-1} \sum_{i=1}^{n}\left(Y_{i}-\bar{Y}\right)^{2}
\end{aligned}
$$

In these equations, $X$ and $Y$ represent Cartesian loca- tion coordinates, $i$ denotes the order in which observations were collected, $n$ represents the number of observations used in the calculation, and $m$ is the number of pairs of successive observations used.

For a reasonably large set of independent points $(\geq 30)$ sampled from a stable home range, $t^{2} / r^{2}$ is normally distributed with a mean of two (Swihart and Slade $1985 b$ ). Using a test developed by Swihart and Slade $(1985 b)$ for use with $t^{2} / r^{2}$, we determined iteratively the time interval at which successive locational observations were negligibly autocorrelated. For example, if data were collected using a sampling interval of $1 \mathrm{~h}$ between observations, $t^{2} / r^{2}$ was calculated for $\Delta t=1$ $\mathrm{h}$ by using all pairs of points separated by $1 \mathrm{~h}$. This value of $t^{2} / r^{2}$ was then used to test the null hypothesis of independence between observations separated by 1 h. Subsequently, $t^{2} / r^{2}$ was calculated and tested for all pairs of points separated by $2 \mathrm{~h}, 3 \mathrm{~h}$, etc., until three successive values of $\Delta t$ resulted in levels of autocorrelation not significantly different at the .25 level (Swihart and Slade $1985 b, 1986)$. The first of the three time intervals was designated the "time to independence," TTI. TTI represented the time interval at which an animal's current position was influenced only by its pattern of home range use, not by its position $\Delta t \mathrm{~min}$ utes earlier. Thus, $T T I$ was the minimum time interval over which an animal could occur, in a probabilistic sense, anywhere in its home range. In this sense, TTI was inversely related to the rate of home range use (Swihart and Slade 1985b). We chose TTI over other measures because it estimates an organism's rate of 
home range use based on the distance travelled per unit time relative to the overall pattern of use of the home range, i.e., $T T I$ is a time measure sensitive to the spatial ecology of the organism. Time variables such as running speed (Calder 1983) and daily distance moved (e.g., Garland 1983) have less bearing on ecological aspects of movement (but see Ford 1983). For example, although the two paths in Figure 1 cover the same distance in a day, they clearly represent different patterns of home range use. Clockwise movement through home range $A$ such that each quadrant is revisited every 4 th $\mathrm{d}$ results in a $T T I$ value for A 1.67 times as great as for home range $B$.

Measurement of $T T I$ was robust to deviations in the underlying distributions of home range use, but it did rely on the assumption that an animal occupied a stable home range. This assumption was verified by subdividing each data set in a chronological sequence and visually inspecting the position of the animal over time. If an individual was judged as shifting its center of activity, it was not used in subsequent analyses.

All allometric relationships were estimated by linear regression performed on logarithmic transformations (base 10) of both body mass and the dependent variable.

\section{RESULTS}

\section{Rates of home range use}

A size-dependent movement clock appears to govern home range use in mammals. Using all species, $T T I=$ $247 M^{0.36}\left(R^{2}=0.49, P<.01\right)$. Thus, a 50-g mammal uses its home range $\approx 12$ times as fast as a $50-\mathrm{kg}$ individual. Furthermore, the exponent of 0.36 does not differ significantly $(P>.10)$ from $1 / 4$, consistent with the hypothesis that home range use should scale with $M$ in the same fashion as physiological times (i.e., $t=$ $a M^{\prime / 4}$.

Rates of home range use varied with diet. For croppers, the regression of $T T I$ on $M$ yielded an exponent of 0.22 , but the regression was not significant $\left(R^{2}=\right.$ $0.16, P=.12$; Fig. 2$)$. Much of the reason for the poor fit could be ascribed to the extremely low $T T I$ value of the pika, Ochotona princeps (Fig. 2). Deletion of pikas resulted in the equation $T T I=336 M^{0.17}\left(R^{2}=\right.$ $0.36, P<.05)$. The exponent, 0.17 , did not differ significantly $(P>.05)$ from $1 / 4$.

The relationship between body mass of hunters and rate of home range use, $T T I=195 M^{0.49}$, was significant $\left(R^{2}=0.79, P<.001\right.$; Fig. 2). The exponent of 0.49 relating $T T I$ with $M$ for hunters was significantly $(P<.05)$ greater than the $1 / 4$ value characterizing physiological times. Interpretation of this exponent as evidence against the generality of the $1 / 4$ scaling rule is premature, however, because the small and large hunters in our study differed in foraging modes. The six smallest hunter species were classified as central place foragers, whereas the remaining hunters were nonCPF species (Table 1). The only CPF species classified as a
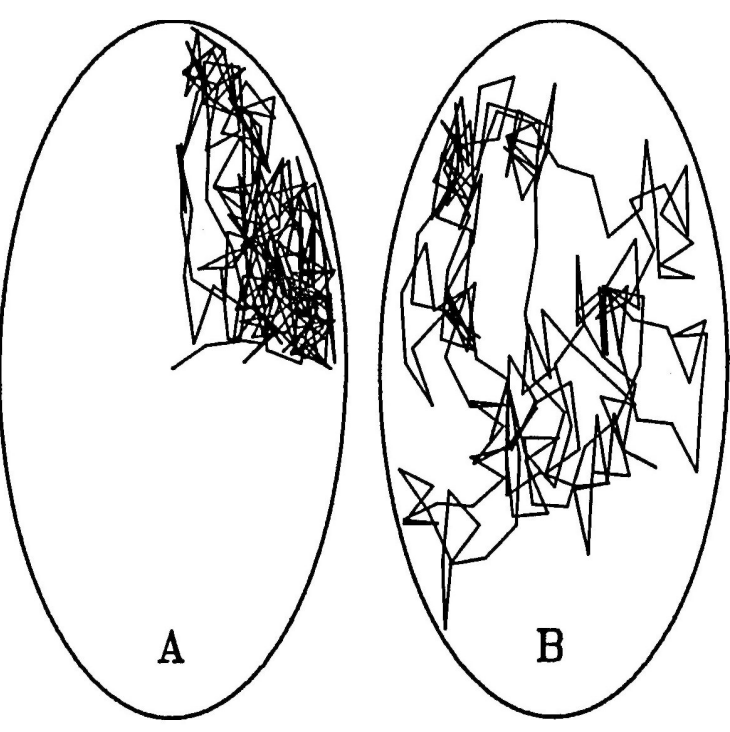

Fig. 1. Illustration of different patterns of home range use. Both paths occur in home ranges of equal size and cover equal distances in a unit of time. However, path $\mathrm{A}$ is concentrated in a small portion of the home range relative to path $B$. This difference in temporal use of the home range would not be reflected in a measure such as daily movement distance, but it would be reflected by TTI. (TTI is the minimum time interval between successive position records necessary for the two positions to be considered statistically independent.)

cropper in our study was the pika, the species deviating most from the observed relationship between $T T I$ and $M$ for that trophic class (Fig. 2).

For nonCPF species regardless of diet, TTI = $354 M^{0.22}\left(R^{2}=0.50, P<.01 ;\right.$ Fig. 3$)$, and the exponent of 0.22 did not differ from $1 / 4$. Body mass of central place foragers was not a good predictor of $T T I(P>$ $.50)$, perhaps because of the small range of sizes spanned by species exhibiting this foraging mode (Table 1, Fig. 3). Foraging mode was important in setting rates of home range use; $C P F$ species moved about their home ranges approximately five times as fast as nonCPF species of similar size (Fig. 3).

\section{Home range size}

For all species, home range area in hectares was related to body mass in kilograms as $A=8.51 M^{1.42}\left(R^{2}=\right.$ $0.73, P<.001)$. The scaling exponent of 1.42 was significantly greater $(P<.01)$ than the exponent of $3 / 4$ predicted from size-dependent metabolic requirements. Harestad and Bunnell (1979) also reported a scaling exponent significantly greater than $3 / 4$. Their finding was based on data from 55 species of mammals, only 10 of which were represented in the current study.

Home ranges of croppers were related to body mass as $A=4.90 M^{1.56}\left(R^{2}=0.80, P<.01\right.$; Fig. 4) and those of hunters as $A=15.14 M^{1.26}\left(R^{2}=0.68, P<.01\right.$; Fig. 4). The exponents of 1.56 and 1.26 were not significantly different $(t=0.82$ with $19 \mathrm{df}, P>.80)$, a char- 


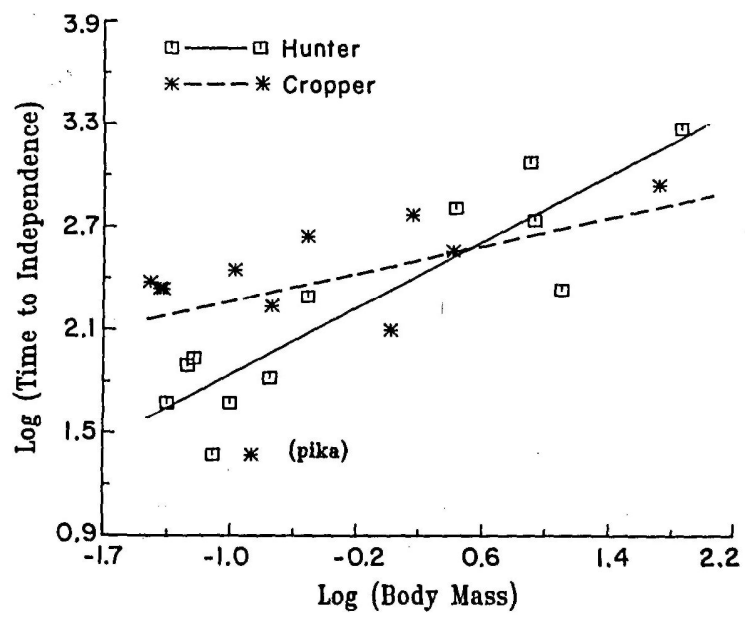

FIG. 2. Allometric relationships between body mass (measured in kilograms) and the temporal component of home range use (TTI, measured in minutes). Note the small TTI value for the pika, the only cropper species classified as a central place forager.

acteristic shared by the data of Harestad and Bunnell (slope exponent $b=1.03$ for croppers, 1.28 for hunters; $t=1.18, P>.10)$ and $\mathrm{McNab}(1963)(b=0.65$ for croppers, 0.82 for hunters, $t=1.60, P>.10$; we reanalyzed McNab's data using weighted averages for species with data from more than one source). For all three data sets, intercept values were larger for hunters than croppers (this study: 15.1 vs. 4.9 ; Harestad and Bunnell: 51.3 vs. 3.2 ; McNab: 7.2 vs. 1.1 ), and this result was significant $(P<.05)$ for all but the present study $(t=0.28, P>.80)$. In general, then, home ranges of hunters and croppers scaled similarly with body mass, but for comparably sized species, home ranges of hunters were larger than those of croppers.

Home ranges of nonCPF species were related to body mass as $A=6.10 M^{1.63}\left(R^{2}=0.83, P<.001\right.$; Fig. 5). As with our analysis of $T T I$, the range of $M$ for CPF species was too small to detect any relation with $A$. No consistent differences were apparent in the sizes of home ranges of comparably sized CPF and nonCPF species (Fig. 5).

\section{DisCUSSION}

\section{Temporal scaling of home range use}

Our results generally support the hypothesis that the temporal component of home range use is related to $M^{1 / 4}$. Interestingly, mammalian life-spans also are related to $M$ with an exponent of $\approx 1 / 4$ (Sacher 1959). Thus, even though small mammals traverse their home ranges more rapidly in a chronological sense, during a lifetime small and large mammals appear to use their ranges with equal intensity.

Differences in annual activity provide a partial explanation for the faster mass-specific rates exhibited by central place foragers. All CPF species in the present study cache food. When resources are abundant, individuals of these species forage for maintenance requirements and also for food to store. We hypothesize that the rate of home range use necessary to meet only current energy requirements would more closely parallel rates of similar-sized nonCPF species. This pattern was evident in intra-individual variation in home range use by the chipmunk Tamias umbrinus (Bergstrom 1986). During a 2-wk period in 1983, a lactating female's $T T I$ averaged $85 \mathrm{~min}$. The energy requirements of lactation presumably would dictate that all of her foraging time be directed toward meeting current needs. Thus, visits to the central place were infrequent and involved nursing as opposed to caching. During intensive nest-building preceding parturition, however, her TTI was $45 \mathrm{~min}$, due to the high frequency with which the central place was visited. The same female was pregnant the following spring and was often observed caching food; her TTI during this period was $55 \mathrm{~min}$. The lower energetic demands of pregnancy relative to those of lactation presumably enabled the pregnant female to spend more time caching, i.e., to forage in a manner more typical of a CPF species. In addition, the increased frequency of visits to the nest might have lowered $T T I$ by increasing the frequency of radial movements from the edge of the home range to the nest and hence the rate at which $t^{2}$ approached $2 r^{2}$.

Environmental factors that influence intraspecific or intra-individual variation in rates of space use have been identified in other taxa. Swihart and Johnson (1986) suggested that the rate of territory use by adult American Robins (Turdus migratorius) was a function of nestling ontogeny; as young approached fledging age, adults traversed their territory at an increasingly rapid rate. Rate of patch use increased with decreasing re-

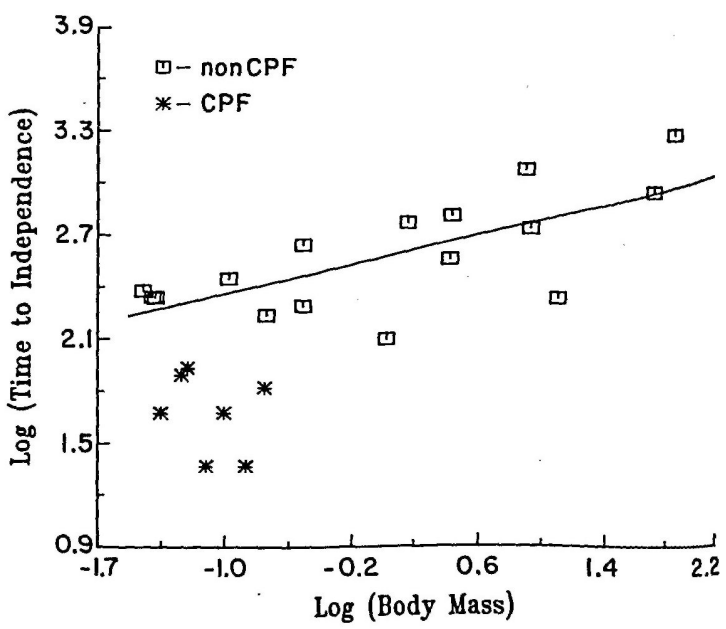

FIG. 3. Influence of foraging mode and body mass (measured in kilograms) on the temporal component of home range use (TTI, measured in minutes). The regression line is for noncentral place foragers. 


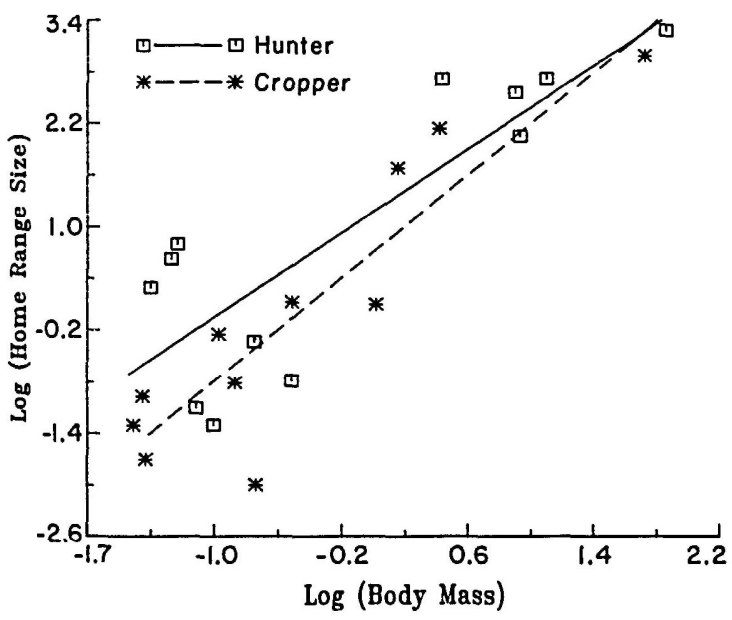

FIG. 4. Scaling of home range size (measured in hectares) with body mass (measured in kilograms) for mammals categorized by trophic class.

source density in houseflies (Musca domestica), but hunger level had no effect (R. K. Swihart and W. J. Bell, personal observation). Sexual differences may also occur; male birds of paradise (Parotia lawesii) used their home ranges faster than females (S. Pruett-Jones, personal communication).

Numerous factors could influence our estimates of $T T I$. Several species in our study used three-dimensional home ranges. Schoener's ratio is strictly applicable only for two-dimensional movement; thus, our values of $T T I$ may be biased for scansorial or fossorial species, the degree of bias depending on the frequency, velocity, and patterns of vertical movements. In addition, use of a different statistic for estimating home range size might alter the magnitudes of the values obtained from relating $A$ to $M$, as would different statistics of rate of space use (cf. Ford 1983, Tracy and Christian 1986).

Estimates of home range size are biased when locational data are autocorrelated, especially for models relying on knowledge of the distribution of use of the home range (Swihart and Slade 1985a). An important practical implication of our findings is that the relation between $T T I$ and mass can be used as a guideline to select objectively an independent subset of data for statistical analysis, because observations separated by TTI minutes are negligibly autocorrelated. Of course, this does not preclude use of the complete data set to construct activity budgets or use patterns as long as a reasonable sampling protocol is followed (see Samuel and Garton 1987).

\section{Time and home range size}

Like home range size, $T T I$ is a statistic used to describe one aspect of an individual's pattern of space use. As such, both $A$ and $T T I$ are produced by an animal's movements, and neither should be viewed as a causative agent governing the other. It is more informative to view variations in $A$ and $T T I$ in relation to environmental features and physiological or morphological factors. For example, our data indicate that rate of home range use is influenced by foraging mode (Fig. 3). Clearly, an animal's mobility is a function of its morphology (McNab 1963). In addition, variations in $A$ have been ascribed to differences in habitat productivity (Harestad and Bunnell 1979) and social organization (Damuth 1981).

Knowledge of the size dependency of $T T I$ provides greater insight into the association between home range size and habitat quality. Harestad and Bunnell (1979) hypothesized that perceived habitat productivity varied negatively with body mass, thereby accounting for relationships between $A$ and $M$ with exponents greater than $3 / 4$. From a forager's perspective, the quality of the habitat is a function of the effective density of edible biomass, i.e., the density of resources after accounting for differences in capture probabilities, and the time necessary for exploited patches to renew themselves. Large mammals traverse their home ranges at slower rates than do small mammals (Figs. 1 and 2), their revisitation times are longer, and thus they perceive the renewal time as longer than do small mammals occupying an identical area. For Harestad and Bunnell's (1979) hypothesis to be tenable, the positive association between mass and perceived renewal time must be offset by a negative relation between body mass and perceived density of food. Harestad and Bunnell (1979) modeled home range area $(A$, with a scaling exponent $k$ ) as a function of metabolic requirements $(M R$, energy/time) and habitat productivity $(P$, energy . area $^{-1} \cdot$ time $^{-1}$ ) such that $A=M R / P$. By subdividing $P$ into perceived standing crop ( $P S C$, energy/area) and

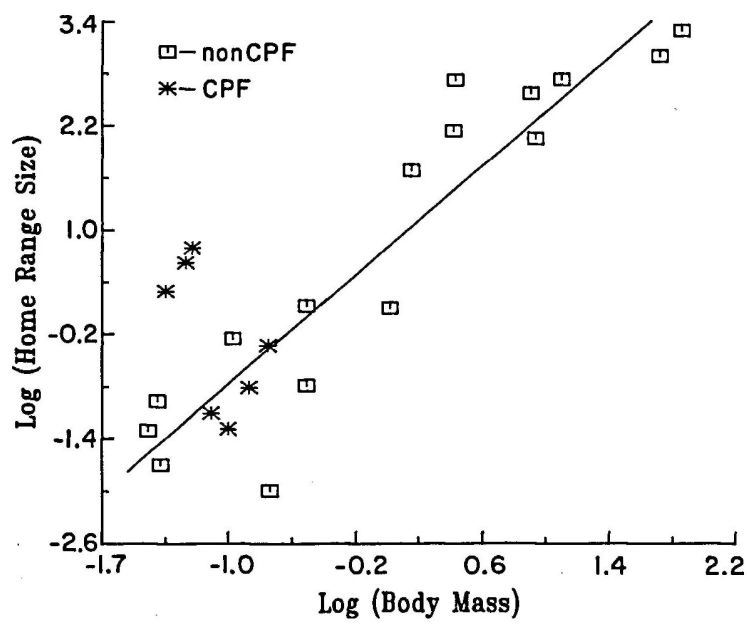

FIG. 5. Influence of foraging mode and body mass on home range scaling. The line refers to the relation between home range size (measured in hectares) and body mass (measured in kilograms) for noncentral place foragers. 
the perceived time necessary for renewal ( $P R R$, time), it is easy to solve for $P S C: P S C=(M R \times P R R) / A$. If perceived renewal time is proportional to $T T I, P S C$ is proportional to $\left(M^{3 / 4} \times M^{1 / 4}\right) / M^{k}=M^{1-k}$. Substituting 1.42 , the value of $k$ in our study, would require that the perceived density of food be related to $M^{-0.42}$. Accordingly, the density of food perceived by a $50-\mathrm{kg}$ mammal should be only $19 \%$ of that perceived by a 1 -kg individual if the hypothesis of Harestad and Bunnell (1979) is correct.

Social organization has also been invoked as a cause for home ranges scaling with body mass to an exponent $>3 / 4$. J. Damuth (1981 and personal communication) has shown that the degree of home range sharing increases with body size in herbivorous and carnivorous mammals. Thus, an individual would need to cover a range large enough so that the area available for its exclusive use (from an energetic rather than a behavioral perspective) is sufficient to satisfy its metabolic demands (i.e., $M^{3 / 4}$ ). Damuth (1981) concluded that this exclusive area is related to $M^{3 / 4}$ for herbivores.

Home range sharing may result from two quite distinct mechanisms: sharing in social species due to aggregative behavior, or sharing in solitary species due to encroachment by conspecifics (Swihart 1986). Sociality increases with size in both canids (Bekoff et al. 1981) and ground dwelling sciurids (Armitage 1981), presumably in response to size-dependent physiological characteristics such as maturation time (Armitage 1981). It is interesting that maturation time is related to $M^{1 / 4}$ (sources in Lindstedt and Calder 1981, Thompson 1987 ), and $1 / 4$ is not statistically different from the exponent of 0.36 describing the relationship between $M$ and the degree of home range sharing in herbivores (Damuth 1981). Note, though, that home range sharing could scale positively with body size in mammals even in the absence of size-dependent sociality, because the slower rate of space use by large species makes their home ranges more susceptible to exploitation by conspecifics. So regardless of the proximate mechanism generating sharing of space, it appears that the ultimate cause is a size-dependent biological time.

We have shown that the rate at which some mammals use their home ranges is related to body mass. Our results also suggest that the ecological time scale influencing movements is related to body mass in a manner analogous to physiological times such as heartbeat duration, lending support to the idea that ecological traits are largely natural consequences of the physiological parameters underlying them (Calder 1983). Nonetheless, rates of home range use are influenced by behavior and ecology, as illustrated by the importance of foraging mode. Finally, the ecological time scale governing home range use may help to explain the allometric relation between home range and body mass by extending our understanding of social organization and habitat productivity as factors affecting home range size.

\section{ACKNOWLEDGMENTS}

We are especially grateful to the researchers who donated their data for analysis (Table 1); without their generosity, this study would not have been possible. These individuals, with the species donated in parentheses, were: G. Cameron (Geomys attwatteri), F. S. Dobson (Spermophilus columbianus, $S$. beecheyi), E. Fritzell (Urocyon cinereoargenteus), T. Getty (Tamias striatus), Z. Halpin (Cynomys ludovicianus), S. Hill (Dipodomys ingens), M. Horner (Ursus americanus), F. Knowlton (Canis latrans), D. Madison (Microtus pennsylvanicus), T. Reynolds (Antilocapra americana), A. Smith (Ochotona princeps), G. Smith (Lepus californicus), J. Tester (Procyon lotor, Lepus americanus), P. Waser (Cercocebus albigena), and N. Wells (Tamiasciurus hudsonicus). B. Danielson assisted R. K. Swihart in collecting data on Microtus ochrogaster and Synaptomys cooperi. John Damuth, Larry Wolf, and an anonymous reviewer greatly improved the manuscript with their comments. In addition, we thank Donald Aylor, Michael Conover, Robert Hoffmann, Thor Holmes, Mike Johnson, Dirk Van Vuren, and members of the mammal discussion group at the University of Kansas for their thoughtful critiques. Tom Eagle, Don Siniff, and Peter Jordan assisted the senior author in data retrieval at the University of Min. nesota. Computer facilities were supplied by the Academic Computing Center at The University of Kansas.

\section{LITERATURE CITED}

Armitage, K. B. 1981. Sociality as a life-history tactic of ground squirrels. Oecologia (Berlin) 48:36-49.

Bekoff, M., J. Diamond, and J. B. Mitton. 1981. Life-historj patterns and sociality in canids: body-size, reproduction, and behavior. Oecologia (Berlin) 50:386-390.

Bergstrom, B. J. 1986. Ecological and behavioral relationships among three species of chipmunks (Tamias) in the Front Range of Colorado. Dissertation. University of Kansas, Lawrence, Kansas, USA.

Blueweiss, L., H. Fox, V. Kudzma, D. Nakashima, R. Peters, and S. Sams. 1978. Relationships between body size and some life history parameters. Oecologia (Berlin) 37:257272.

Calder, W. A., III. 1983. Ecological scaling: mammals and birds. Annual Review of Ecology and Systematics 14:213230 .

1984. Size, function and life history. Harvard University Press, Cambridge, Massachusetts, USA.

Damuth, J. 1981. Home range, home range overlap, and species energy use among herbivorous mammals. Biological Journal of the Linnaean Society 15:185-193.

Eisenberg, J. F. 1981. The mammalian radiations. University of Chicago Press, Chicago, Illinois, USA.

Ford, R. G. 1983. Home range in a patchy environment: optimal foraging predictions. American Zoologist 23:31j326.

Garland, T., Jr. 1983. Scaling the ecological cost of transport to body mass in terrestrial mammals. American Naturalist 121:571-587.

Gittleman, J. L., and P. H. Harvey. 1982. Carnivore homerange size, metabolic needs and ecology. Behavioral Ecology and Sociobiology 10:57-63.

Harestad, A. S., and F. L. Bunnell. 1979. Home range and body weight -a reevaluation. Ecology 60:389-402.

Lindstedt, S. L., and W. A. Calder III. 1981. Body size, physiological time, and longevity of homeothermic animals. Quarterly Review of Biology 56:1-16.

Lindstedt, S. L., B. J. Miller, and S. W. Buskirk. 1986. Home range, time, and body size in mammals. Ecology 67:413418 .

McNab, B. K. 1963. Bioenergetics and the determination of home range size. American Naturalist 97:133-139.

Sacher, G. A. 1959. Relation of lifespan to brain weight and 
body weight. Pages 115-141 in G. E. W. Wolstenholme and M. O'Connor, editors. The lifespan of animals. Little, Brown, Boston, Massachusetts, USA.

Samuel, M. D., and E. O. Garton. 1987. Incorporating activity time in harmonic home range analysis. Journal of Wildlife Management 51:254-257.

Schoener, T. W. 1981. An empirically based estimate of home range. Theoretical Population Biology 20:281-325.

Swihart, R. K. 1986. Home range-body mass allometry in rabbits and hares (Leporidae). Acta Theriologica 31:139148.

Swihart, R. K., and S. G. Johnson. 1986. Foraging decisions of American Robins: somatic and reproductive tradeoffs. Behavioral Ecology and Sociobiology 19:275-282.

Swihart, R. K., and N. A. Slade. 1985a. Influence of sampling interval on estimates of home-range size. Journal of Wildlife Management 49:1019-1025.
Swihart, R. K., and N. A. Slade. 1985b. Testing for independence of observations in animal movements. Ecology 66:1176-1184.

Swihart, R. K., and N. A. Slade. 1986. The importance of statistical power when testing for independence in animal movements. Ecology 67:255-258.

Swihart, R. K., and N. A. Slade. 1987. A test for independence of movements as shown by live trapping. American Midland Naturalist 117:203-207.

Thompson, S. D. 1987. Body size, duration of parental care, and the intrinsic rate of natural increase in eutherian and metatherian mammals. Oecologia (Berlin) 71:201-209.

Tracy, C. R., and K. A. Christian. 1986. Ecological relations among space, time, and thermal niche axes. Ecology 67: 609-615.

Western, D. 1979. Size, life history and ecology in mammals. African Journal of Ecology 17:185-204. 